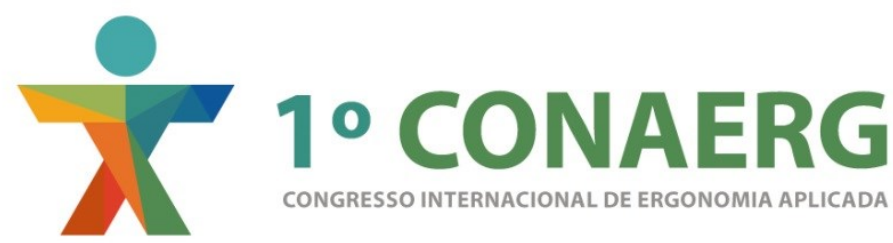

\section{ANÁLISE COMPARATIVA DA USABILIDADE DE MODELOS DE FORNO DE MICRO-ONDAS}

\author{
Edeilson Vicente Ferreira (1);
}

Paula Araújo Azevedo (2);

Marcelo M. Soares (3);

Marcelo Francisco Gomes (4)

(1) Universidade Federal de Pernambuco, Programa de Pós-Graduação em Ergonomia, Enfermeiro Especialista em Enfermagem do Trabalho. email: edeilsonvicente@gmail.com

(2) Universidade Federal de Pernambuco, Programa de Pós-Graduação em Ergonomia, Enfermeira Especialista em Enfermagem em Saúde da Família e-mail: paula azevedoaraujo@hotmail.com

(3) Universidade Federal de Pernambuco, Programa de Pós-Graduação em Ergonomia, Ph.D. em ergonomia, e-mail: soaresmm@gmail.com

(4) Universidade Federal de Pernambuco, Programa de Pós-Graduação em

Ergonomia, Pedagogo especialista em gestão educacional e-mail: marceloh2@yahoo.com.br

\begin{abstract}
RESUMO
Este artigo estuda a ergonomia e a usabilidade aplicada a dois fornos micro-ondas a partir da percepção de seis usuários, focando em modelos e técnicas de usabilidade. O objetivo principal foi analisar a usabilidade e interface de um produto antigo e de um atual para identificar os principais problemas na interface do sistema humano-tarefa-máquina. Com base no conceito da usabilidade definido pela ISSO 9241-11, verificou-se que ambos apresentam problemas, seja quanto à usabilidade, seja quanto às especificações técnicas indicadas pelos fabricantes. Assim, verificamos que a escolha do melhor produto depende das necessidades dos usuários, conhecimentos técnicos e características do problema.
\end{abstract}

Palavras Chaves: Usabilidade, Interface e conhecimento técnico.

\footnotetext{
ABSTRACT

This article studies the ergonomics and usability applied to two microwave ovens from the perception six users, focusing on models and usability techniques. The main objective was to
} 
analyze the usability and interface of an old product and a current to identify the main problems in the human task-machine interface system. Based on the usability concept defined by ISO 9241-11, it was found that both have problems, either as usability, whether the technical specifications set by the manufacturers. Thus, we find that the choice of the best product depends on the needs of users, technical knowledge and characteristics of the problem.

Key words: Usability, Interface and technical knowledge.

\section{INTRODUÇÃO}

De acordo com Jordan (1998), considerando a evolução tecnológica alcançada nas mais diversas áreas do conhecimento, os produtos utilizados no ambiente doméstico têm ficado cada vez mais complexos. Apesar disso, esses produtos ainda não são capazes de exercer suas funções de maneira autônoma. Nessa perspectiva, é consensual entre os estudiosos da ergonomia e usabilidade que, no planejamento de um produto, é necessário privilegiar a interação do sistema humanotarefa-máquina (SHTM), pois ao enfatizar a interação entre os usuários e as máquinas (independentemente de elas serem simples ou complexas), esse sistema possibilita a compreensão de que a máquina deve estar adaptada aos seus usuários, servindo conforme seus objetivos de forma prática, segura e confortável.

Há um consenso no fato de que produtos difíceis de usar não são agradáveis e consequentemente não propiciam satisfação aos usuários. O projeto ergonômico implica na aplicação da informação ergonômica ao design de ferramentas, máquinas, sistemas, tarefas, trabalhos e ambientes para o uso humano seguro, confortável e efetivo (CHAPANIS , 1996).

Segundo apontam MORAES e MONT'ALVÃO (2012), em qualquer sistema de equipamentos utilizam-se ou envolvem-se pessoas, pois os sistemas são preparados necessariamente com algum objetivo humano. Logicamente, a intensidade com que os sistemas envolvem operadores humanos é bastante variável, considerando que uns projetam, outros constroem, outros implantam, etc. e, finalmente, outros usam, e usam de formas variadas. Assim, tanto humanos quanto máquinas são fundamentais para o desempenho do sistema. Não existe um sistema completamente automático, ou completamente manual.

A usabilidade corresponde à questão específica de saber se as pessoas são capazes de usar determinado produto. Outros conceitos, tais como prazer, aceitação do consumidor ou como as pessoas irão usar, comprar ou desfrutar de um produto, devem complementar a usabilidade, conforme sugerem Kahman \& Henze (2002). Com tudo, a usabilidade é um dos muitos conceitos avaliativos para descrever a experiência do consumidor no uso de um produto.

Ao observar tais definições, pode-se concluir que estas compartilham dos seguintes aspectos: A existência de um usuário; que este desempenha uma atividade; que está usando um produto; que o produto está sendo utilizado em um determinado contexto; em um ambiente definido (Falcão \& Soares, 2012).

lida (2016), afirma que a usabilidade não depende apenas das características do produto, mas também do usuário, dos objetivos pretendidos e do ambiente em que o produto é usado, ou seja, da interação entre o produto, o usuário, a tarefa e o ambiente. Por consequência, um produto pode ter níveis significativamente diferentes de usabilidade quando usado em diferentes contextos. 
Neste sentido, do mesmo modo que os diversos produtos de consumo são inseridos no mercado, os eletrodomésticos têm tido uma grande avanço tecnológico, levando para o ambiente doméstico grande variedade de equipamentos, que muitas vezes são projetados para um usuário-padrão, mas não consideram a ampla variedade de usuários e suas diferenças individuais, que pode ir de uma criança ao idoso, com diversos níveis de diferenças físicas e cognitivas. Desta forma, é visível no cotidiano do ambiente doméstico que as máquinas utilizadas para a realização das tarefas possuem inadequações ergonômicas que dificultam a realização de suas funções ao desconsiderar diversas diferenças individuais.

Assim, este estudo objetiva principalmente estabelecer uma comparação entre dois fornos de micro-ondas e com isso analisar a usabilidade percebida pelos seus usuários.

\section{METODOLOGIA}

\subsection{Objetos de Estudo:}

Dois fornos de micro-ondas que desempenham funções básicas para o processamento do alimento.

A máquina $A$ pertence à marca Gourmet Wave, com capacidade de 18 litros. Suas especificações técnicas estão descritas na Tabela 1. O aparelho desempenha funções básicas de preparação e aquecimento de alimentos no ambiente doméstico, como legumes, peixes, carnes, massas, batata, pizza, sopa e mingau (Figura 1). Todas as funções são indicadas em um painel digital no qual as teclas são niveladas à superfície em que estão inseridas. O equipamento possui, ainda, funções básicas de autorreaquecimento, relógio para ajuste prévio, velocidade de descongelamento, descongelar por peso, parar e iniciar. Por meio do teclado numérico, o usuário pode indicar o tempo a que deseja submeter o alimento. No seu interior, há um espaço para depósito de recipientes destinado à preparação do alimento.

Tabela 1 - Especificações técnicas do Forno 1

\begin{tabular}{|l|l|l|l|}
\hline MODELO & $\begin{array}{l}\text { EM720CKE- } \\
\text { POOB }\end{array}$ & $\begin{array}{l}\text { FREQ. } \\
2450 \mathrm{MHZ}\end{array}$ \\
\hline TENSÃO & $220 \mathrm{~V}$ & POTÊNCIA & $1,2 \mathrm{KW}$ \\
\hline FREQUÊNCIA & $60 \mathrm{HZ}$ & VOLUME & 18 LITROS \\
\hline
\end{tabular}


Figura 1 - Painel de controle a máquina A.

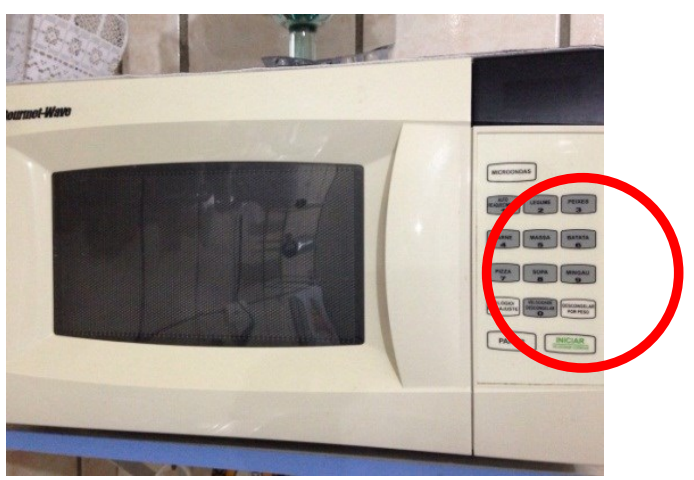

A máquina B pertence ao modelo Facilite Middi, da marca Consul, com capacidade para 25 litros. Suas especificações técnicas estão descritas na Tabela 2. O aparelho desempenha funções descritas como Todo dia (arroz, carne moída, omelete, macarrão, legumes e salsicha) e Diversão (pipoca, pudim e brigadeiro). Além disso, possui as funções de descongelamento (prato pronto e carnes) e aquecer. Por meio do teclado numérico, o usuário pode indicar o tempo ou a potência a que deseja submeter o alimento, ligar por +30 segundos e cancelar. No seu interior, há um espaço para depósito de recipientes destinado à preparação do alimento. Todas as funções são indicadas em um painel digital no qual as teclas são niveladas à superfície em que estão inseridas.

Figura 2 - Painel de controle de funções da máquina B

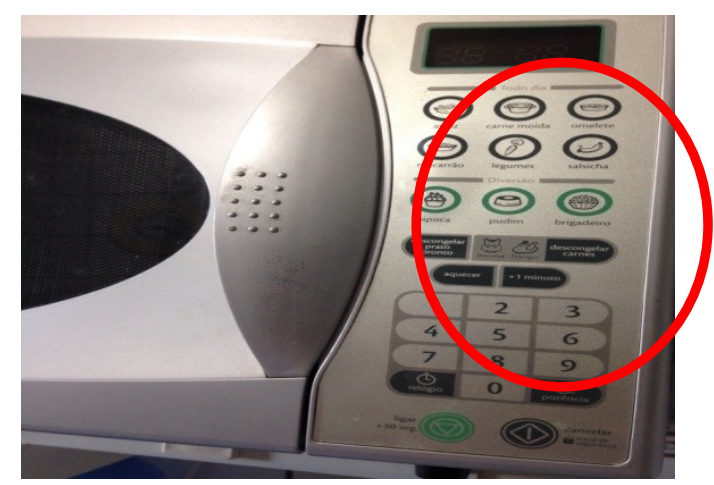

Tabela 2 - Especificações técnicas do Forno 2

\begin{tabular}{|l|l|l|l|l|l|}
\hline MODELO & CMY3OARBNA & TENSÃO & $220 \mathrm{~V}$ & \multicolumn{3}{|c|}{$\begin{array}{l}\text { FREQ. } \\
2450 \mathrm{MHZ}\end{array}$} \\
\hline VERSÃO & 00 & FREQUÊNCIA & $60 \mathrm{HZ}$ & POTÊNCIA & $1,4 \mathrm{KW}$ \\
\hline SÉRIE & ME 0622309 & CORRENTE & $12 \mathrm{~A}$ & VOLUME & 25 LITROS \\
\hline
\end{tabular}




\subsection{Desenho do estudo:}

Foi desenvolvida uma pesquisa na qual foi desenvolvida uma metodologia descritiva e qualiativa.

\subsection{Amostra:}

Para participar da pesquisa, foram selecionados seis participantes, escolhidos aleatoriamente, de diferentes perfis (Tabela 3), classificados de acordo com sua expertise, conforme LEVENTHAL e BARNES (1998). Os participantes foram divididos em dois grupos, cada um com três usuários (Grupo 1 e Grupo 2). O Grupo 1 utilizou a máquina $A$ de marca Brastemp que possuiu tecnologia mais atualizada em seu ambiente doméstico. O Grupo 2, por sua vez, utilizou a máquina $B$ também de marca Brastemp de um modelo mais antigo sem muito acesso tecnológico, seu ambiente doméstico. Todos os usuários têm, dentro do seu contexto diário, contato com interfaces de aparelhos eletrônicos e eletrodomésticos, como televisão, máquina de lavar, computador, telefone celular e forno de micro-ondas.

Tabela 3 - Caracterização dos usuários.

\begin{tabular}{|c|c|c|c|c|c|c|}
\hline \multirow[b]{2}{*}{ GRUPO } & \multirow[b]{2}{*}{ IDENTIFICAÇÃO } & \multicolumn{2}{|c|}{ SEXO } & \multirow[b]{2}{*}{ IDADE } & \multirow[b]{2}{*}{$\begin{array}{l}\text { GRAU DE } \\
\text { INSTRUÇÃO }\end{array}$} & \multirow[b]{2}{*}{ CLASSIFICAÇÃO* } \\
\hline & & $\mathbf{M}$ & $\mathbf{F}$ & & & \\
\hline 1 & $\mathbf{A L}$ & & $\mathbf{X}$ & 51 & MÉDIO & EXPERIENTE \\
\hline 1 & AD & $\mathbf{X}$ & & 60 & MÉDIO & OCASIONAL \\
\hline 1 & $\mathbf{A Z}$ & & $\mathbf{X}$ & 76 & $\begin{array}{l}\text { FUNDAMENTAL } \\
\text { (INCOMP) }\end{array}$ & NOVATO \\
\hline 2 & CR & & $\mathbf{x}$ & 33 & $\begin{array}{l}\text { FUNDAMENTAL } \\
\text { (INCOMP) }\end{array}$ & EXPERIENTE \\
\hline 2 & LE & $\mathbf{X}$ & & 32 & SUPERIOR & OCASIONAL \\
\hline 2 & MA & & $\mathbf{x}$ & 65 & $\begin{array}{l}\text { MÉDIO } \\
\text { (INCOMP) }\end{array}$ & NOVATO \\
\hline
\end{tabular}

* De acordo com LEVENTHAL e BARNES (1998).

\subsection{Instrumentos de coleta de dados:}

O método da observação foi realizado de forma aleatória. Essa observação é realizada sem planejamento e sem controle aprioristicamente definidos, sobre fenômenos que ocorrem de modo imprevisto. Sendo possível, com isso, obter-se uma amostra da situação muito próxima da realidade dos usuários. Além disso, foi considerada o relato das atividades através da coleta dos depoimentos dos usuários que operaram o sistema, durante o uso dos mesmos, com a aplicação de questionário. Com isso, foi possível obter os relatos diretos em relação aos problemas encontrados a fim de compará-los posteriormente segundo MORAES e MONT'ALVÃO (2012).

Cada usuário foi observado usando o produto em suas residências, com o intuito de utilizar o programa de processamento do alimento nas duas máquinas A e B. Durante a realização do procedimento, solicitou-se a verbalização das suas ações durante o processo, enquanto estavam sendo observados pelos pesquisadores. Para fazer a 
verbalização das atividades, foram coletados depoimentos dos usuários posteriormente, e na análise individual, os participantes descreveram verbalmente as etapas que seguiram no processo de cozimento do alimento. Seguiu-se após a observação do desenvolvimento das atividades, o preenchimento do questionário.

\section{RESULTADOS E DISCUSSÃO}

Os usuários que participaram desta pesquisa possuíam faixa etária de 32 a 76 anos. Quatro deles são do sexo feminino e dois do sexo masculino. O nível de escolaridade, dois com ensino médio incompleto, um com nível médio, um com nível médio incompleto e um com ensino superior completo. Dentre os usuários, dois afirmaram que usavam o forno de micro-ondas diariamente, sendo classificados como experientes. Outros dois relataram usar o produto esporadicamente, sendo classificados de usuários ocupacionais. E concluindo os outros dois participantes foram convidados a reproduzir o procedimento de processamento do alimento pela primeira vez, sendo chamados de usuários novatos.

Após o levantamento feito a partir da observação, verbalização e aplicação do questionário, foram listados os principais problemas nos SHTM analisados, tendo como base a categorização e taxonomia dos problemas ergonômicos. O início da análise se deu com a observação do desenvolvimento das tarefas em ambos os equipamentos e os voluntários foram submetidos ao seu uso no mesmo local onde os aparelhos se encontram instalados no ambiente doméstico.

Após o levantamento obtido a partir da verbalização e da observação com os usuários, foram listados os principais problemas de Interface Produto Usuário:

- Problemas posturais;

- Problemas informacionais;

- Problemas Instrumentais;

- Problemas cognitivos.

$\mathrm{Na}$ utilização do Forno 1, observou-se que todos os usuários apresentaram dificuldades posturais, pois o equipamento está posicionado na diagonal do corpo do usuário (Figura 3), ocasionando um desvio lateral (1) de sua coluna vertebral (postura escoliótica). Esse posicionamento dificulta a visualização do painel de controle (2) e torna perigosa a tarefa de inserir e retirar o alimento do aparelho. Entendemos que este problema postural está diretamente relacionado a posicionamento da instalação do equipamento, mas, no caso avaliado, apresenta-se como um extremo da inadequação na instalação de um equipamento desta natureza.

Figura 3 - 0 Usuário 3 realizando a tarefa de retirar o alimento da máquina 1

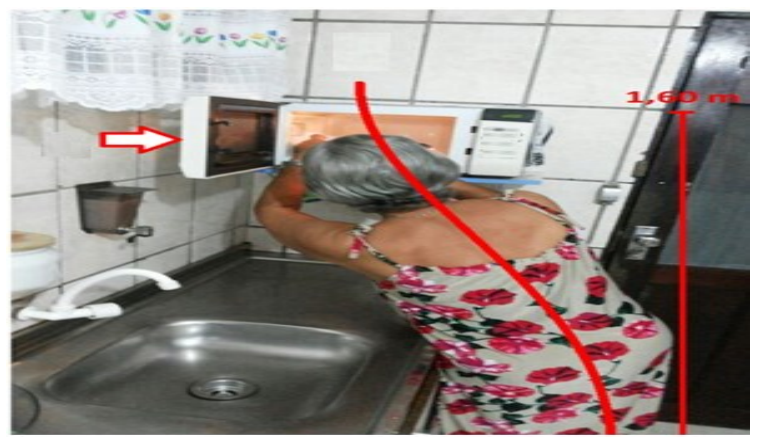


Ainda na análise do Forno 1, foi observado o Usuário 3 (Grupo 1), que o equipamento também estava instalado a uma altura inadequada $(1,60 \mathrm{~m})$. O mau posicionamento da máquina foi comentado pelos três usuários do Grupo 1 através da verbalização.

Apesar da Usuária 3 ter uma estatura corporal baixa $(1,58 \mathrm{~m})$, o posicionamento transversal da máquina (1) dificulta ainda mais a visualização do display. Além disso, o Usuário 3 relatou já ter sua acuidade visual diminuída onde dificulta a realização das atividades, conforme relato a seguir:

"Tenho dificuldade pra colocar a comida nele porque acho ele muito alto para eu alcançar, e ele está todo virado pra pia. Aí fica difícil de ver direito, pois eu tenho catarata."

Já no Forno 2, observou-se que o equipamento está instalado a uma altura inadequada (1,80 m) para o Usuário 1 (Grupo 2), cuja estatura é de 1,60 m (Figura 4) e para o Usuário 3 , cuja estatura é de $1,65 \mathrm{~m}$. Desta forma, para ambos utilizarem o equipamento é necessário o uso de uma escada para poder manusear o painel de controle e suas funções. Ainda assim, a utilização se mostrou inadequada, pois o uso da escada torna perigosa a tarefa de inserir/retirar o alimento, principalmente quando o forno encontra-se aquecido, conforme relato espontâneo do Usuário 1:

"Fico preocupada da tigela não ficar no meio do prato e escorregar em cima de mim quando abrir a porta, pois ele tá meio inclinado. E também não consigo ver direito, porque tá alto, então preciso usar a escada."

\section{Figura 4 - 0 Usuário 1 realizando a tarefa de selecionar o tempo para aquecer um alimento.}

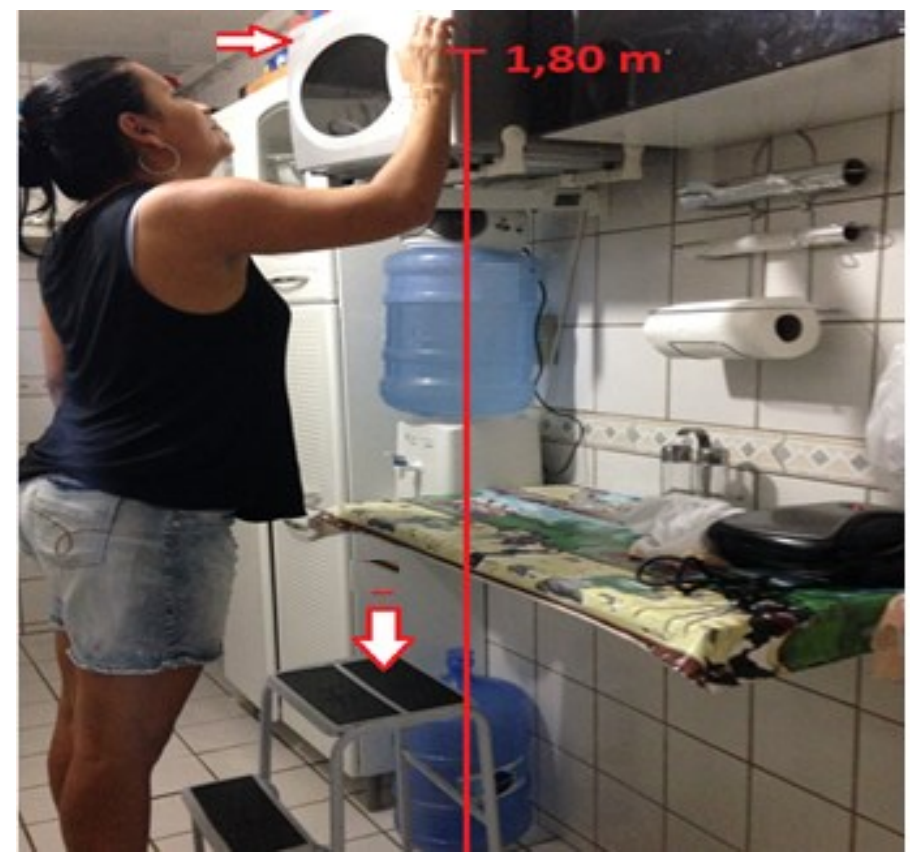

Observou-se que todos os usuários começam o processo escolhendo o alimento desejado, colocando-o em recipientes de diferentes materiais, de acordo com a quantidade, o tipo e o tempo desejado. Para iniciar o preparo do alimento, os usuários, sem exceções, escolheram, unicamente, o tempo para reaquecimento. Dentre os seis 
usuários, dois (os experientes) utilizavam o forno sem dificuldades, porém só utilizavam o botão do display destinado ao reaquecimento. Os dois usuários novatos analisados não sabiam por onde começar o processo de seleção de programas no painel de controle de funções dos equipamentos, ou seja, não sabiam qual botão acionar primeiro. A análise dos fornos permitiu a observação de alguns problemas informacionais associados a essa dificuldade de iniciar a tarefa relatada pelos dois usuários novatos.

No Forno 1, as teclas apresentam o mesmo formato e são diferenciadas entre si pelas palavras que contém e pela cor. Apesar de haver essa diferenciação, na prática ela se verificou problemática, pois o tamanho dos caracteres é pequeno e as cores nada mais são que variações de tons de cinza, o que não leva o usuário a associar as cores às ações que deseja executar.

Já no Forno 2, a iluminação das teclas apresenta pouco contraste com a superfície na qual estão inseridas e todas elas possuem o mesmo formato e cor (resultante do contraste). Dessa forma, a distinção entre a função de uma tecla e outra se dá exclusivamente por meio da leitura das palavras inseridas em cada tecla.

O Usuário 1 (Grupo 2) relatou certa preocupação quanto à instalação do Forno 2, que se encontra inclinado e localizando entre dois armários, o que dificulta a saída do ar quente dissipado pelo motor da máquina. Na Figura 2, é possível visualizar, também, que sob o equipamento há um aparelho de som. Conforme indicado no manual de ambos os fornos, os usuários não devem instalar o aparelho próximo de outros eletrodomésticos que emitam ondas, pois a interferência de frequência pode projudicar o seu funcionamento.

Por fim, em ambos os fornos, observou-se que as teclas do painel de funções encontram-se niveladas à superfície na qual estão inseridas, o que dificulta a identificação das mesmas. Por esse motivo, é comum os usuários imprimirem mais força do que o necessário para acionar os botões, pois supõem que há necessidade de imprimir teclas, quando, na verdade, os teclados são sensíveis ao toque. Estes problemas informacionais foram observados em relatos espontâneos dos usuários ocasionais e novatos dos dois grupos.

Importante dizer que, além de as teclas estarem no mesmo nível da superfície da qual fazem parte, elas não possuem codificação em Braile para auxiliar os deficientes visuais.

Os usuários ocasionais e novatos também apresentaram certa dificuldade na leitura dos textos do painel, sendo comum a escolha pelo botão de reaquecimento, pois já haviam memorizado a sua localização no painel de controle de funções dos aparelhos. Já os botões destinados ao preparo de alimentos expecíficos (indicados por ícones e palavras) não foram utilizados pelos voluntários. Todos relataram não utilizar esses botões por acreditar que eles não ajudam no preparo adequado dos alimentos. Apesar disso, os seis voluntários relataram que não tinha interesse em buscar informações nos manuais dos equipamentos para que possam utilizá-los melhor, pois julgam-nos de difícil compreensão por apresentarem uma leitura "chata e cansativa".

Os usuários experientes dos dois grupos relataram certa preocupação com a limpeza da parte exterior e interior dos aparelhos. Em conversa espontânea disseram temer danificar o seu funcionamento caso utilizassem um produto de limpeza inadequado ou realizassem o procedimento de maneira incorreta. Questionados se consultaram o manual a fim de resolver esse problema, ambos confessaram que não. No entanto, mesmo que fossem ao manual se informar sobre como realizar a limpeza de forma adequada, os usuários não encontrariam a informação desejada. Enquanto o manual 
do Forno 1 recomenda apenas o uso de um pano úmido (o que é insuficiente para uma higienização satisfatória), o manual do Forno 2 alerta o usuário para utilizar somente "produtos adequados", mas não esclarece que produtos são esses.

A análise dos dois sistemas mostrou que ambos apresentam problemas acionais associados à abertura da porta, que apresnta certa resistência. Assim, é preciso imprimir certa força tanto para abri-la quanto para fechá-la. Some-se a isso que, no Forno 2, o movimento de abrir/fechar é sempre marcado por um barulho, resultado da grande resistência da trava.

\subsection{Parecer ergonômico}

De acordo com a apriorização dos problemas levantados, o parecer ergonômico se apresenta como uma síntese, indicando os passos seguintes para o diagnóstico através da formulação dos problemas e sugestões preliminares de melhoria.

Tabela 4 - Apresenta quadro de formulação dos problemas levantados e algumas sugestões de melhoria.

\begin{tabular}{|c|c|c|c|c|c|c|}
\hline \multicolumn{7}{|c|}{ Formulação de Problemas } \\
\hline & Problema & $\begin{array}{l}\text { Requerimentos } \\
\text { de Design }\end{array}$ & $\begin{array}{l}\text { Problemas } \\
\text { Humanos }\end{array}$ & $\begin{array}{c}\text { Custos } \\
\text { Humanos }\end{array}$ & Sugestões & $\begin{array}{c}\text { Limitações do } \\
\text { sistema }\end{array}$ \\
\hline \multicolumn{7}{|c|}{ INTERFACE } \\
\hline 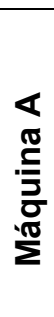 & $\begin{array}{l}\text { Display não } \\
\text { fica no campo } \\
\text { de visão do } \\
\text { usuário que } \\
\text { tem acuidade } \\
\text { visual } \\
\text { diminuída. }\end{array}$ & $\begin{array}{l}\text { Display no } \\
\text { campo de visão } \\
\text { adequado }\end{array}$ & $\begin{array}{l}\text { Esforço } \\
\text { excessivo para } \\
\text { acionar o Display } \\
\text { da máquina por } \\
\text { está fora da linha } \\
\text { de alcance }\end{array}$ & $\begin{array}{l}\text { Dores nos } \\
\text { membros } \\
\text { superiores } \\
\text { e } \\
\text { possíveis } \\
\text { retrabalho } \\
\text { s }\end{array}$ & $\begin{array}{l}\text { Adequação } \\
\text { da } \\
\text { localização } \\
\text { do display }\end{array}$ & $\begin{array}{l}\text { Condicionamento } \\
\text { do display à } \\
\text { posição do forno } \\
\text { de micro-ondas } \\
\text { A. }\end{array}$ \\
\hline 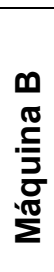 & $\begin{array}{l}\text { Display não } \\
\text { fica no campo } \\
\text { de visão do } \\
\text { usuário }\end{array}$ & $\begin{array}{l}\text { Display no } \\
\text { campo de visão } \\
\text { do usuário }\end{array}$ & $\begin{array}{l}\text { Utilização de } \\
\text { escada para } \\
\text { acionar a } \\
\text { máquina }\end{array}$ & $\begin{array}{l}\text { Risco para } \\
\text { quedas }\end{array}$ & $\begin{array}{l}\text { Adequação } \\
\text { da } \\
\text { localização } \\
\text { do display }\end{array}$ & $\begin{array}{l}\text { Condicionamento } \\
\text { do display à } \\
\text { posição } \\
\text { adequada para } \\
\text { utilização dos } \\
\text { usuários }\end{array}$ \\
\hline 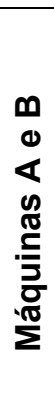 & $\begin{array}{l}\text { Localização } \\
\text { imprópria } \\
\text { para } \\
\text { utilização do } \\
\text { equipamento }\end{array}$ & $\begin{array}{l}\text { Espaço } \\
\text { dimensionado } \\
\text { para } \\
\text { manipulação } \\
\text { correta dos } \\
\text { fornos de } \\
\text { micro-ondas }\end{array}$ & $\begin{array}{l}\text { Desconforto pelo } \\
\text { mau } \\
\text { posicionamento } \\
\text { para preparar o } \\
\text { alimento }\end{array}$ & $\begin{array}{l}\text { Possível } \\
\text { fadiga } \\
\text { muscular } \\
\text { e visual. }\end{array}$ & $\begin{array}{l}\text { Espaço } \\
\text { físico maior, } \\
\text { distantes de } \\
\text { armários, } \\
\text { paredes, } \\
\text { eletrodomés } \\
\text { ticos e com } \\
\text { boa } \\
\text { ventilação. }\end{array}$ & $\begin{array}{l}\text { Há outro local } \\
\text { disponível para } \\
\text { os equipamentos } \\
\text { serem instalados }\end{array}$ \\
\hline
\end{tabular}




\begin{tabular}{|c|c|c|c|c|c|c|}
\hline \multicolumn{7}{|c|}{ COGNITIVO } \\
\hline 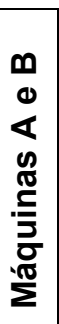 & $\begin{array}{l}\text { Deficiência } \\
\text { na lógica } \\
\text { operacional } \\
\text { resultante } \\
\text { do layout do } \\
\text { painel de } \\
\text { controle }\end{array}$ & $\begin{array}{l}\text { Consideração dos } \\
\text { estereótipos de } \\
\text { operacionalização } \\
\text { do equipamento } \\
\text { para o usuário }\end{array}$ & $\begin{array}{l}\text { Dificuldade de } \\
\text { operacionaliza } \\
\text { ção do } \\
\text { equipamento }\end{array}$ & $\begin{array}{l}\text { Estresse e } \\
\text { retrabalho }\end{array}$ & $\begin{array}{l}\text { Sequenciame } \\
\text { nto dos } \\
\text { mesmos } \\
\text { botões para } \\
\text { preparar o } \\
\text { alimento }\end{array}$ & $\begin{array}{l}\text { Falta de } \\
\text { interesse do } \\
\text { fabricante e dos } \\
\text { usuários para } \\
\text { ler o manual do } \\
\text { produto }\end{array}$ \\
\hline \multicolumn{7}{|c|}{ INSTRUMENTAIS } \\
\hline 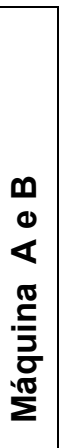 & $\begin{array}{l}\text { O mostrador } \\
\text { prioriza as } \\
\text { funções mais } \\
\text { utilizadas, no } \\
\text { entanto, os } \\
\text { usuários } \\
\text { utilizam } \\
\text { sempre as } \\
\text { mesmas } \\
\text { teclas }\end{array}$ & $\begin{array}{l}\text { Utilizar } \\
\text { mostradores } \\
\text { considerando a } \\
\text { priorização das } \\
\text { funções }\end{array}$ & $\begin{array}{l}\text { Indução do } \\
\text { acionamento } \\
\text { da mesma } \\
\text { tecla }\end{array}$ & $\begin{array}{l}\text { Não } \\
\text { interesse } \\
\text { pelo } \\
\text { produto }\end{array}$ & $\begin{array}{l}\text { Ordenamento } \\
\text { dos botões } \\
\text { do display do } \\
\text { painel de } \\
\text { controle por } \\
\text { priorização } \\
\text { das funções }\end{array}$ & $\begin{array}{l}\text { Falta de } \\
\text { interesse do } \\
\text { fabricante e do } \\
\text { usuário. }\end{array}$ \\
\hline \multicolumn{7}{|c|}{ INFORMACIONAL } \\
\hline 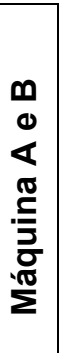 & $\begin{array}{l}\text { Alguns } \\
\text { botões } \\
\text { possuem a } \\
\text { função } \\
\text { representad } \\
\text { a apenas } \\
\text { por } \\
\text { símbolos }\end{array}$ & $\begin{array}{l}\text { Botões com } \\
\text { funções } \\
\text { representados } \\
\text { também na } \\
\text { linguagem escrita }\end{array}$ & $\begin{array}{l}\text { Não } \\
\text { reconhecimen } \\
\text { to ou má } \\
\text { interpretação } \\
\text { das ações dos } \\
\text { botões }\end{array}$ & $\begin{array}{l}\text { Estresse e } \\
\text { retrabalhos }\end{array}$ & $\begin{array}{l}\text { Demonstrar a } \\
\text { função dos } \\
\text { botões de } \\
\text { forma escrita } \\
\text { e cores } \\
\text { diversas }\end{array}$ & $\begin{array}{l}\text { Espaço } \\
\text { disponível do } \\
\text { painel de } \\
\text { controle } \\
\text { Falta de } \\
\text { interesse do } \\
\text { fabricante }\end{array}$ \\
\hline
\end{tabular}

\section{CONSIDERAÇÕES FINAIS}

Um produto (ou sistema) quando é desenvolvido, será usado dentro de um contexto particular e por uma população de utilizadores com determinadas características (Maguire, 2001). Neste aspecto, a usabilidade do produto não é uma atividade independente e está relacionada ao contexto. A alteração de qualquer aspecto relevante ao contexto de uso pode alterar a capacidade de utilização do produto (Bevan \& Macleod, 1994).

Com isso, a análise comparativa dos dados dos dois produtos nos permite concluir que os dois fornos de micro-ondas utilizados no estudo apresentaram diversos problemas ergonômicos, considerando a categorização e taxonomia dos problemas conforme enfocadas aqui (problemas posturais, instrumentais, informacionais e acionais). Assim, alguns problemas identificados foram decorrentes de falhas no planejamento dos equipamentos, enquanto outros são resultados do desconhecimento das informações presentes nos manuais do usuário, considerados pelos informantes como "chatos e cansativos", outros da escolha inadequada do local de instalação do produto. 
Sentiram-se satisfeitos com os aparelhos ao realizarem as tarefas propostas. Apesar de terem apresentado certa dificuldade em acionar os produtos no primeiro momento.

Os fornos analisados apresentaram, portanto, problemas interfaciais importantes. Esses problemas foram agravados pela instalação e uso inadequados dos mesmos. Tem-se, aqui, uma combinação bastante prejudicial ao sistema humano-tarefamáquina: maquinas com falhas de planejamento instaladas e/ou operadas por usuários inabilitados.

\section{REFERÊNCIAS}

ABERGO (Brasil). O que é ergonomia. 2014. Disponível em: <http://www.abergo.org.br/internas.php?pg=o_que_e_ergonomia>. Acesso em: 28 out. 2014.

Bevan, N. \& Macleod, M. 1994. Usability Measurement in Context. Behaviour and Information Technology 13(1-2): 132-145.

GOMES FILHO, João. Ergonomia do objeto: Sistema técnico de leitura ergonômica. 2. ed. São Paulo: Escrituras, 2010.

IIDA, Itiro. Ergonomia: projeto e produção. 2. ed. São Paulo: Blücher, 2005.

Jordan, P.W. 1998. An introduction to usability. London: Taylor \& Francis.

Kahman, R. \& Henze, L. 2002. Mapping the User- Product Relationship (in Product Design). In Green, W.S. and Jordan, P.W. (Eds.). Pleasure with Products: Beyond Usability. Taylor and Francis: London.

LEVENTHAL, Laura; BARNES, Julie. Usability engineering: process, products and examples. London: Pearson, 1998.

Maguire, M. 2001. Context of Use within Usability Activities. International journal of HumanComputer Studies, 55(4): 453-483.

MELO, Alessandra Fernandes de. Avaliação da Usabilidade em Eletrodomésticos: O caso do forno de microondas doméstico. Florianópolis, 2000. 105f. Dissertação (Mestrado em Engenharia de Produção) - Programa de Pós-graduação em Engenharia de Produção, UFSC, 2000.

MORAES, Anamaria de; MONT'ALVÃO, Claudia. Ergonomia: conceitos e aplicações. 4. ed. Rio de Janeiro: 2ab, 2012.

MORAES, Anamaria de (Org.). Ergonomia informacional: Avisos, advertências e projeto de sinalização. Rio de Janeiro: luser, 2002.

PEQUINI, Suzi Mariño. Ergonomia aplicada ao Design de produtos: Um estudo de caso sobre o design de bicicletas. 2005. $152 \mathrm{f}$. Tese (Doutorado) - Curso de Arquitetura e Urbanismo, USP, São Paulo, 2005.

ROSA, José Guilherme Santa; MORAES, Ana Maria de. Design Participativo. Rio de Janeiro: Rio Book's, 2012.

WALTER, Silvana Anita; TONTINI, Gérson; LIMA, Edmilson de Oliveira. Identificação de oportunidades de melhoria em um curso de administração por meio de métodos qualitativos de processamento de informação. Revista de Negócios, Blumenau, v. 4, n. 11, p.21-37, out. 2006. 